\title{
Interventions aiming to reduce time to antibiotics (TTA) in patients with fever and neutropenia during chemotherapy for cancer (FN), a systematic review
}

\author{
Christa Koenig $^{1,2}$ (D) Christine Schneider ${ }^{1} \cdot$ Jessica E. Morgan $^{2,3}$ (D) $\cdot$ Roland A. Ammann $^{1}$ (D) Lillian Sung $^{4}$ (D) \\ Bob Phillips ${ }^{2,3}$ (D)
}

Received: 11 June 2019 / Accepted: 22 August 2019 / Published online: 5 September 2019

(C) The Author(s) 2019

\begin{abstract}
Purpose Multiple interventions have been developed aiming to reduce time to antibiotics (TTA) in patients with fever and neutropenia (FN) following chemotherapy for cancer. We evaluated their effect to reduce TTA and their impact on important clinical outcomes in a systematic review.

Methods The search covered seven databases. Biases and quality of studies were assessed with the Risk of Bias in Nonrandomized Studies of Interventions (ROBINS-I) tool. Interventions could be implemented in any setting and performed by any person included in the FN management. Absolute change of TTA was the primary outcome. Registration: PROSPERO (CRD42018092948).

Results Six thousand two hundred ninety-six titles and abstracts were screened, 177 studies were retrieved and 30 studies were included. Risk of bias was moderate to serious in 28 studies and low in two studies. All but one study reported a reduction of TTA after the intervention. Various types of interventions were implemented; they most commonly aimed at professionals. Most of the studies made more than one single intervention.

Conclusion This review may help centers to identify their specific sources of delay and barriers to change and to define what intervention may be the best to apply. This review supports the assertion that TTA can be considered a measure of quality of care, emphasizes the importance of education and training, and describes the very different interventions which have effectively reduced TTA.
\end{abstract}

Keywords Oncology · Cancer · Fever · Neutropenia · Time to antibiotics · Quality improvement projects · Systematic review

Electronic supplementary material The online version of this article (https://doi.org/10.1007/s00520-019-05056-w) contains supplementary material, which is available to authorized users.

Christa Koenig

christa.koenig@insel.ch

1 Division of Pediatric Hematology/Oncology, Department of Pediatrics, Inselspital, Bern University Hospital, University of Bern, Freiburgstrasse 15, CH-3010 Bern, Switzerland

2 Centre for Reviews and Dissemination, University of York, York, UK

3 Leeds Children's Hospital, Leeds, UK

4 The Hospital for Sick Children, University of Toronto, Toronto, Ontario, Canada

\section{Background}

In patients with cancer, fever in chemotherapy-induced severe neutropenia $(\mathrm{FN})$ is the most frequent potentially lethal complication of chemotherapy for cancer [1]. When absolute neutrophil count drops below $0.5 \times 10^{9} / \mathrm{L}$ the risk of life-threatening bacterial infection increases [2]. Prompt empirical therapy with broadspectrum antibiotics is standard of care and lethality is below $1 \%$ in pediatric patients $[3,4]$ and approximately $10 \%$ in adult patients [5], but still FN remains the leading cause of emergency hospitalization. Time to antibiotics (TTA) usually refers to the amount of time passed from arrival at the hospital to administration of antibiotics, and despite inconsistent evidence about the association of TTA and clinical outcomes, guidelines [6-8] and experts insist that timely and appropriate antibiotic administration is essential for adequate patient care. TTA $<60 \mathrm{~min}$ is even used as a measure of quality of care [9]. Presuming the beneficial 
effect on patient-important outcomes, several groups have attempted to reduce TTA in patients with FN by implementing specific interventions in emergency departments (ED) and oncology wards. These interventions have never been summarized, so this systematic review aimed to identify and synthesize information on interventions performed, their effect to reduce TTA, and the potential use of these approaches.

\section{Methods}

The protocol for this review was registered on PROSPERO (CRD42018092948) prior to commencing the work and has been published [10]. Simultaneously with this systematic review, we collected information about the association between TTA and clinical outcomes in patients with FN under chemotherapy for cancer, published separately [11]. This section is an adapted version of the methods reported there.

Electronic searches of MEDLINE, MEDLINE In-Process \& Other Non-Indexed Citations, EMBASE, CINAHL, CDSR, CENTRAL, and LILACS were performed on May 9th, 2018. The search was updated on April 5th, 2019. The search strategy included the Medical Subject Heading terms and text words to identify fever and neutropenia and the intervention of treatment with antibiotics. Antibiotics were additionally searched by groups and names of antibiotic drugs (e.g., penicillin, betalactams, quinolones).

In EMBASE search, "time" was added as a required search factor to narrow the results. Studies from 1997 onward were eligible, no language restrictions were applied. Pilot searching took place before the actual search and found all five previous identified studies [12-16]. The full search strategies are provided with the protocol publication [10]. Manual searches of references and forward citation searching of included articles was conducted. Authors of relevant studies and experts within the field were contacted to seek further studies.

\section{Study selection}

Inclusion and exclusion criteria were defined a priori. Studies investigating any intervention or combination of interventions attempting to reduce TTA in adult or pediatric patients with cancer, or after hematopoietic stem cell transplantation, and FN were included. Interventions could be implemented in inpatient or outpatient settings, performed by any person included in the FN management. All kind of studies, except case reports and those presented only as abstract or posters, were eligible.

Outcomes Absolute change of TTA was the primary outcome. Secondary outcomes were TTA measurements other than absolute, safety, and treatment adequacy. Safety was defined as death, admission to intensive care unit (ICU), and/or severe sepsis (including septic shock); treatment adequacy was defined as relapse of primary infection, persistence of fever, and/or recurrence of fever without a new infection. Additional clinical outcomes as microbiologically defined infections, days of fever, length of hospital stay (LOS), modification of antibiotics, new infections, and composite outcomes that each individual study selected were recorded.

Exclusion criteria Studies were excluded if (1) they were not specific to cancer or did not report on this subgroup separately (mixed populations were permitted if $>50 \%$ population were diagnosed with cancer/hematopoietic stem cell transplantation); (2) they did not report TTA; (3) they did not have data of an accurate comparator group, defined as cared for in the same way, in the same setting, and with the same treatment regimens, except of the intervention studied. The comparison group could be of the same cohort and could be observed simultaneously or successively.

Screening One reviewer (CK) screened the title and abstract of all studies for inclusion. A second reviewer (CS) independently screened $60 \%$ of the titles and abstracts. The kappa statistic for agreement was calculated and showed good agreement between reviewers $(k=0.91,95 \%$ confidence interval (CI) 0.87 to 0.94 ). Full text was obtained for all potential articles of interest. All full texts were assessed for eligibility by two reviewers (CK and CS; $k=0.79,95 \%$ CI 0.69 to 0.89 ). Fourteen studies were referred to a third reviewer (RSP), where 11 were excluded.

\section{Data extraction and risk of bias assessment}

Data extraction and risk of bias assessment was done by one reviewer (CK) and independently checked by a second (RAA). Discrepancies were resolved by consensus. Intervention characteristics were collected according to the Cochrane Effective Practice and Organization of Care Review Group (EPOC) data collection checklist [17]. Risk of bias was assessed using the Risk of Bias in Nonrandomized Studies of Interventions (ROBINS-I) tool [18] at the level of the individual study. All articles were included in the review irrespective of the risk of bias.

\section{Statistical methods}

Due to heterogeneity within the implemented interventions, study sites, and participants, meta-analysis was not undertaken and a narrative synthesis was performed. To visually display the results of the primary outcome, reduction of TTA, a forest plot was drawn including all studies for which mean and standard deviation (SD) were reported or could be estimated. In studies only reporting median, interquartile range (IQR) or $95 \%$ confidence intervals of the mean, and SD were estimated assuming a normal distribution (median $=$ mean; $\mathrm{SD}=\mathrm{IQR} / 1.35 ; \mathrm{SD}=$ $95 \% \mathrm{CI} / 3.92 \times \sqrt{n})$ [19]. 


\section{Results}

\section{Overview}

Titles and abstracts from 6296 studies were assessed and 177 full-text articles retrieved. A flow diagram of the study selection is provided in Fig. 1. Thirty studies were included, thirteen in adult [12, 20-31], and seventeen in pediatric patients [16, 32-47], including a total of 1891 and $6820 \mathrm{FN}$ episodes, respectively. Two-third of the studies were undertaken in the USA $(n=20 ; 67 \%)$. There were four multicenter studies (included number of centers, 2 to 4 ) and the vast majority of studies were undertaken in academic hospitals $(n=25$; $83 \%$ ). No randomized or quasi-randomized trials were identified by the searches. Before and after studies were the most commonly used design $(n=29 ; 97 \%)$, in which TTA was evaluated at baseline and after the implementation of an intervention. Various studies collected TTA at multiple time points, but none of them performed an interrupted time series analysis. The remaining study was a retrospective cohort study [26].

Characteristics of included studies are given in Table 1. Most of the interventions were implemented at EDs $(26 ; 87 \%)$. Fever was defined within a temperature range of $\geq 38.0$ to $\geq 38.5^{\circ} \mathrm{C}$. Seventeen studies defined neutropenia as an absolute neutrophil count (ANC) $<0.5 \times$ $10^{9} / \mathrm{L}$ and $/$ or $<1.0 \times 10^{9} / \mathrm{L}$ expected to decrease. Four studies defined neutropenia as ANC $<1.0 \times 10^{9} / \mathrm{L}$. Other definitions were leucocyte count $\leq 4.0 \times 10^{9} / \mathrm{L}$ or $<1.0 \times 10^{9} / \mathrm{L}$, ANC $<0.2 \times 10^{9} / \mathrm{L}$, or $<0.58 \times 10^{9} / \mathrm{L}$ and expected to decrease. TTA was measured from triage or arrival at the hospital to first dose of antibiotics in the majority of studies $(n=26 ; 87 \%)$. One study with adult patients started measurement of time at fever detection [30], one study defined TTA as time from initial provider evaluation to intravenous antibiotic administration, [44], and the third study started measurement at ICU admission [32]. In one study, a definition was lacking [36]. The definitions used per study are displayed in Online Resource 1, Table 1.

\section{Risk of bias}

Study quality and risk of bias assessment identified a moderate or serious risk for bias in all but two of the included studies (Table 1, for full assessment: Online Resource 1, Table 2). Potential confounders for TTA were set at FN diagnosis, localization of presentation (ED versus oncology ward versus oncology outpatient unit), high patient volumes, presence of central line, and knowledge of staff about an ongoing study (Hawthorne effect) [32]. Additionally, risk status of patients, initial illness severity, time of presentation, and administration route of antibiotics were identified as possible but measurable confounders in almost all studies.
Fig. 1 PRISMA flow diagram of identification and selection of eligible studies

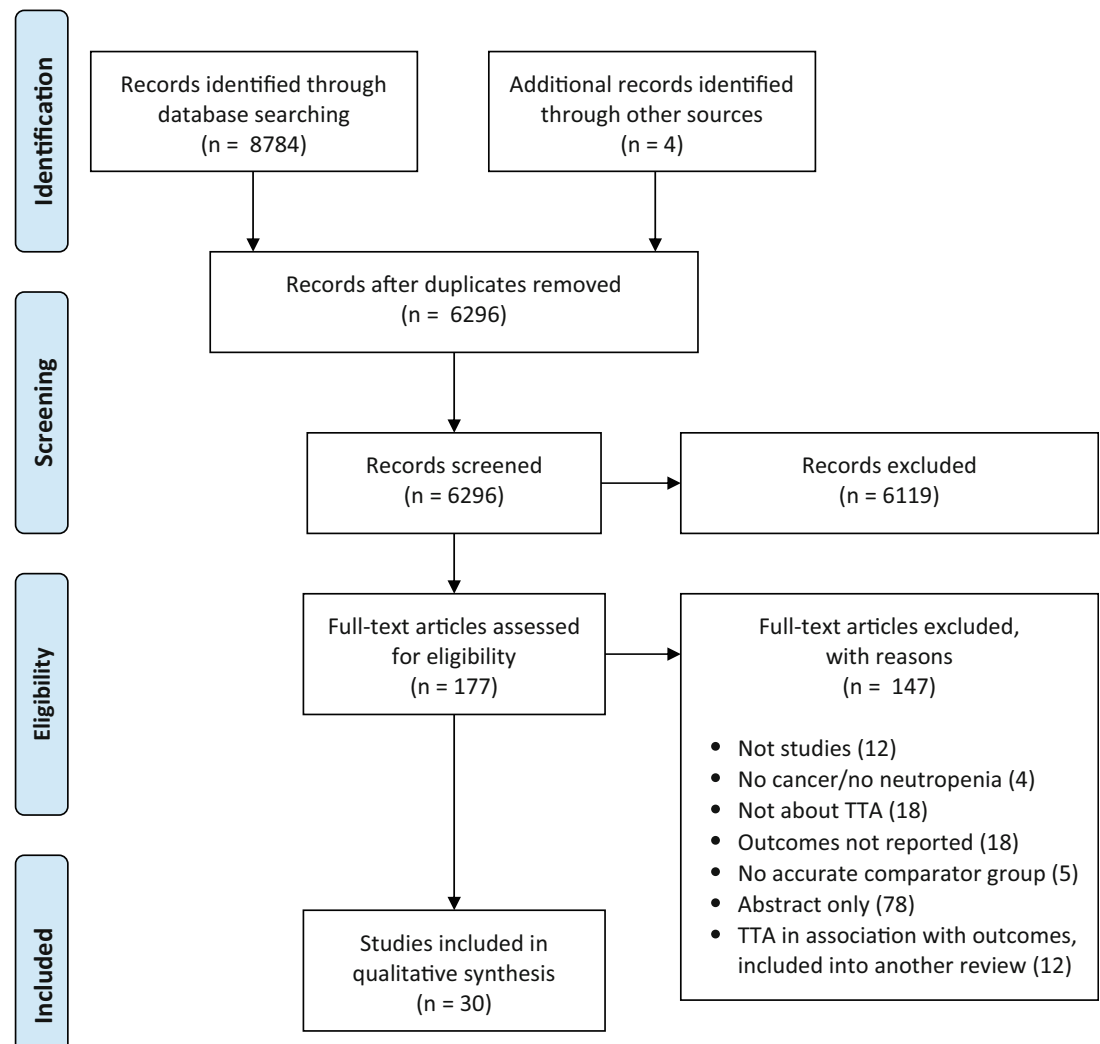




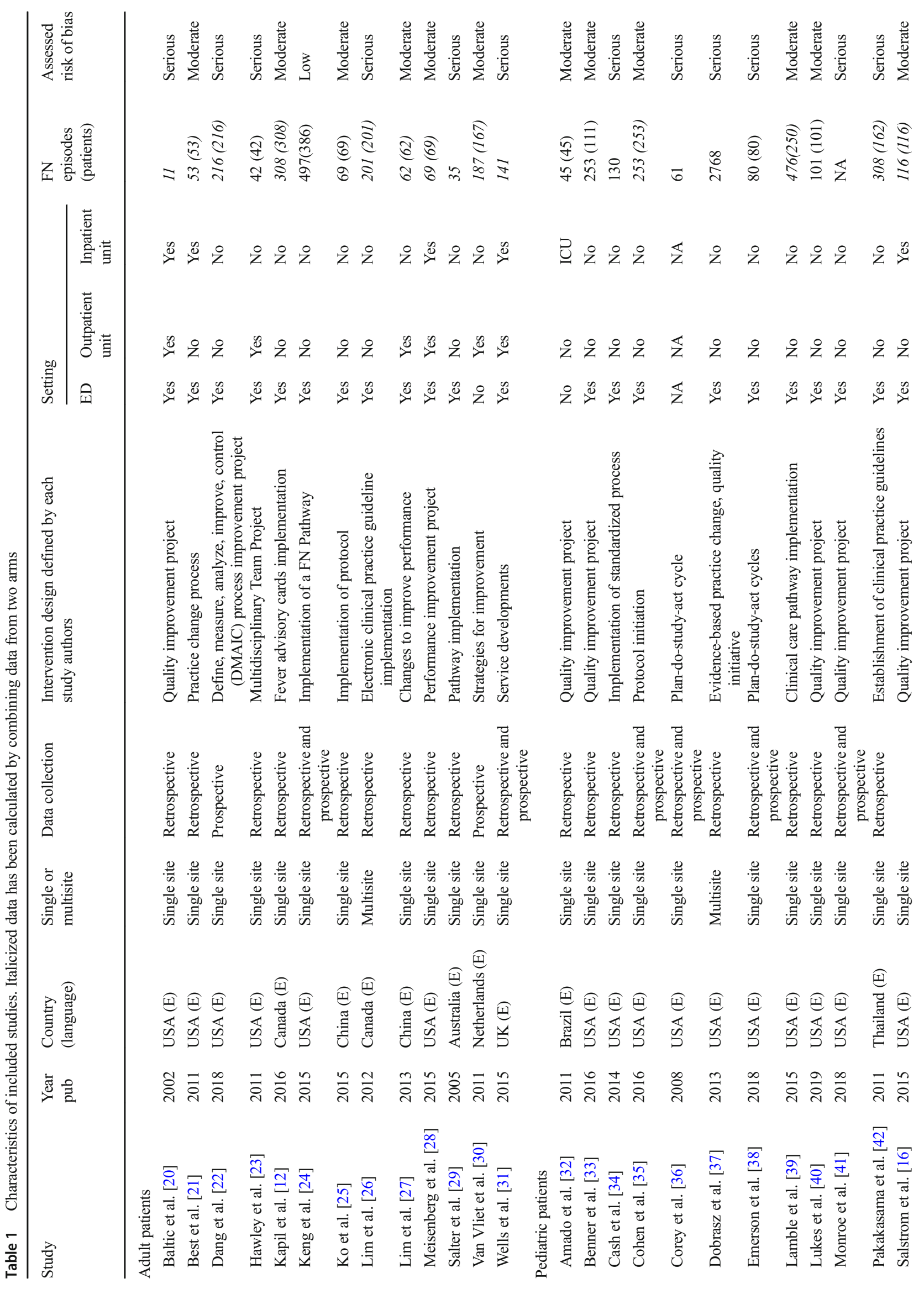




\section{Interventions}

Various types of interventions were implemented, most of the studies made more than one single intervention. Among the thirty studies, the most common group of intervention targeted professionals. They consisted of distribution of FN-Alert cards to patients, skills training, education for staff, and educational updates or feedbacks. Twenty-two studies implemented guidelines, algorithms, or checklists for FN treatment. The collected interventions are summarized in Online Resource 1, Table 3. No study used regulatory or financial interventions.

The studies were indexed to setting, type of intervention, education of staff, implementation of guidelines, algorithms or checklists, and whether they had a follow-up or not (Table 2). Online Resource 1, Table 3 gives an overview of the applied interventions. The number of intervention events varied from 1 to 7 , and duration of intervention was from one single intervention point up to 3 years. Interventions were provided and delivered by local physicians, nurses, pharmacist, laboratory staff, and employees from administration and hospital bed control. One study was supported by hospital quality improvement experts [46] and one by members of the Information Technology department [40]. Unit of allocation and analysis were always the individual patients, and the purpose of recommendation was always appropriate management of these patients.

Targeted behaviors were diagnosis $(n=13)$, test ordering $(n=6)$, procedures $(n=19)$, prescribing $(n=12)$, general management of a problem $(n=19)$, patient education/advice $(n=11)$, and communication between professionals $(n=8)$. To address them, various formats were used like interpersonal, paper, visual, computer, paging system, and phones.

Several articles identified sources of delays and barriers to improve TTA; these are presented separately between adult and pediatric studies in Table 4.

\section{Reduction of TTA}

All 28 studies that compared TTA before and after an intervention reported a reduction in TTA after the intervention (Table 2). Only one of these studies [12], performed in adults, reports a statistically non-significant result, even when TTA declined from a mean of 244 to $195 \mathrm{~min}(p=0.09)$. This study was judged at moderate risk for bias. One study displayed TTA only graphically [36], but equally shows a reduction of TTA. The remaining retrospective cohort study [26] compared TTA in four different hospitals while the intervention was only implemented in one. Likewise, this study showed a significant shorter TTA in the intervention hospital (3.9 versus $4.9 \mathrm{~h}$, $p=0.02$ ).

TTA is reported as continuous variable in all but two studies $[31,41]$. These specific studies only report an increase in 


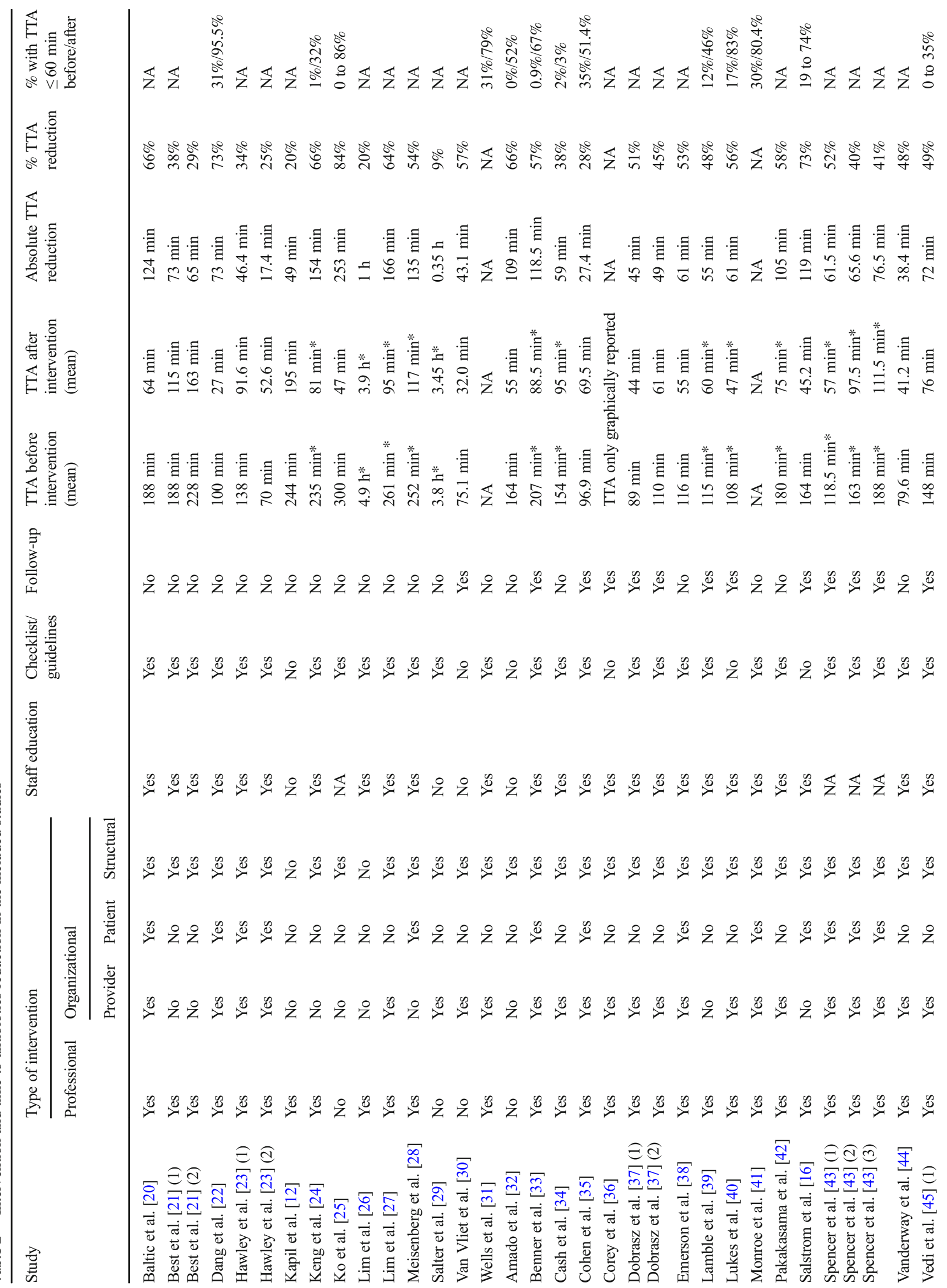


percentage of patients treated within $60 \mathrm{~min}$, as it was reported by several other studies, in addition to continuous TTA (Table 2). The relative reduction of TTA is displayed in Fig. 2 for studies reporting mean and SD or when those parameters could be estimated.

\section{Clinical outcomes}

Safety Most studies were underpowered to address safety (mortality, ICU admission, or occurrence of severe sepsis). Number of deaths was reported by eleven studies [16, 24, $25,31,33,35,36,39,42,43,46]$, with a median mortality of $0 \%$ (maximum $39 \%$ ) before and median mortality of $0 \%$ (maximum 6\%) after the intervention. No significant differences of mortality before and after intervention were detected in seven of these 11 studies. One study only reported the overall number of deaths [43]. One study [25] found an increase in mortality from 0 (0/19 episodes) to $6 \%$ (3/50 episodes; $p<0.05$ ), but these are equally low numbers of deaths and no significant difference was found when death was included into a composite outcome together with serious medical complications $(1 / 19$ versus $7 / 50 ; p=0.45)$. A decrease in mortality was shown in two studies [31, 42]. For adult patients, Wells et al. [31] report a high mortality of 39\% (14 of 36 episodes) before and a mortality of $0 \%$ ( 0 of 79 episodes) after their intervention. Their intervention increased the percentage of patients treated within $60 \mathrm{~min}$ from 14 to $79 \%$, but no absolute times are reported. For pediatric patients, Pakakasama et al. [42] reports a significant reduction in mortality from 6.5 (9 of 138 episodes) before to $0 \%$ ( 0 of 170 episodes; $p=0.001$ ) after the implementation of guidelines. In their study, ICU admission and septic shock were as well significantly reduced after the implementation, 9.4 to $2.9 \%$ ( $p=0.016)$ and 10.9 to $3.5 \%(p=0.011)$, respectively.

Numbers of ICU admissions were reported by eight studies $[24,25,33,35,36,39,42,46]$, with a median of $5 \%$ (maximum $9 \%$ ) before and a median of $1.3 \%$ (maximum 7\%) after the intervention. Only one study [16] found a difference in need for ICU admission before and after the intervention (34\% versus $12.8 \% ; p<0.05$ ). This study describes extending the study period when the results were not significant, without describing the number or nature of the interim analyses. Sepsis was additionally analyzed by one adult study [25], where almost all patients before (84\%) and after the intervention (90\%) were diagnosed with sepsis.

Treatment adequacy No study reported relapses of primary infection, persistence of fever for more than 5 days, or recurrence of fever without a new infection.

Additional outcomes Numbers of patients with an identified source of infection/bacteremia were comparable within the investigated groups before and after the intervention in all 
Table 3 Sources of delays (number of studies reporting) in adult and pediatric patients

\begin{tabular}{|c|c|}
\hline Adult patients & Pediatric patients \\
\hline $\begin{array}{l}\text { Staff related } \\
\text { - Lack of awareness of potential risk/knowledge about FN (5) } \\
\text { - FN patients not recognized (3) } \\
\text { - Difficulties in obtaining central venous access (3) } \\
\text { - Long waiting time for phlebotomist to set up the intravenous line (1) } \\
\text { - Long turn-around time from setting of the prescription by } \\
\text { pharmacist to drug dispensing (1) } \\
\text { - Antibiotics not scheduled as urgency by pharmacist (1) } \\
\text { - Lack of staff (1) } \\
\text { - Long waiting time for initial physician assessment (3) } \\
\text { - Delay related to waiting for a second medical review (1) } \\
\text { - Physician trainees involved in care (1) } \\
\text { - Communication issues (1) }\end{array}$ & $\begin{array}{l}\text { Staff related } \\
\text { - Lack of awareness of potential risk/knowledge about FN (2) } \\
\text { - FN patients not recognized (1) } \\
\text { - Difficulties in obtaining central venous access due to lack of } \\
\text { training/technical difficulties (4) } \\
\text { - No physician available (for examination or order for antibiotics) (4) } \\
\text { - Lack of expertise, fear of treating oncology patients (3) } \\
\text { - Communication with specialist/staff (3) }\end{array}$ \\
\hline $\begin{array}{l}\text { Patient related } \\
\cdot \text { Lack of knowledge of patients (1) }\end{array}$ & $\begin{array}{l}\text { Patient related } \\
\text { - Difficulties in obtaining central venous access due to inadequate } \\
\text { topical analgesia (3) } \\
\text { - Difficulties in obtaining central venous access due to parents } \\
\text { requesting specific nurses/other expectations (3) }\end{array}$ \\
\hline $\begin{array}{l}\text { Procedure related } \\
\text { - Lack of a triage system (1) } \\
\text { - Unavailability of laboratory results (4) } \\
\text { - Missing FN protocols (1) } \\
\text { - Absence of order set (2) } \\
\text { - Large number of patients, multiple concomitant admissions (1) } \\
\text { - Antibiotics not available at emergency (1) } \\
\text { - Delayed administration of antibiotics due to structural issues (3) } \\
\text { (after transfer to inpatient unit, only on next drug round) } \\
\text { - Lack of access to important patient information (1) } \\
\text { Day of the week (1) }\end{array}$ & $\begin{array}{l}\text { Procedure related } \\
\text { - Unawareness of patient arrival (1) } \\
\text { - Difficulties in obtaining central venous access due to lack of } \\
\text { equipment (1) } \\
\text { - Unavailability of laboratory results (6) } \\
\text { - Antibiotics not available at emergency (5) } \\
\text { - Two separate policies for BMT and non-BMT patients (1) } \\
\text { - ED crowding/Competing unwell patients (1) } \\
\text { - No exam/infusion room available, room not prepared (2) } \\
\text { - Guidelines not accessible (1) } \\
\text { - Patient information cannot be entered into the computer system } \\
\text { until the patient's arrival on the unit (1) } \\
\text { - Lack of access to important patient information (1) }\end{array}$ \\
\hline
\end{tabular}

$B M T$, bone marrow transplant; $E D$, emergency department; $F N$, fever and neutropenia

Table 4 Barriers to change (number of studies reporting) in adult and pediatric patients

\begin{tabular}{|c|c|}
\hline Adult patients & Pediatric patients \\
\hline Staff related & Staff related \\
\hline $\begin{array}{l}\text { - Disempowerment of clinicians diagnosing and caring for the patient (1) } \\
\text { - Lack of understanding, ignorance or stubbornness, concerns with } \\
\text { lack of autonomy (physician) (2) } \\
\text { - Lack of order set compliance, low guideline usage (2) } \\
\text { - Lack of communication between professionals (1) } \\
\text { - Lack of ongoing education (1) } \\
\text { - ED overcrowding, (not enough staff) (1) }\end{array}$ & $\begin{array}{l}\text { - Persisting mind-set to confirm neutropenia before antibiotics (1) } \\
\text { - False sense of security: "just another FN patient" (1) } \\
\text { - Lack of knowledge due to rotating residents/medical students (1) } \\
\text { - Education difficulties due to part-time and rotate shifts (2) } \\
\text { - Lack of guideline compliance (3) } \\
\text { - Forgetting the availability of standard dose of antibiotics (1) } \\
\text { - Overwhelming workload, priorities for other patients (2) }\end{array}$ \\
\hline Patient related & Patient related \\
\hline $\begin{array}{l}\text { - Fever alert card unsuitable for some patients (to big, neglect the } \\
\text { replacement of a full card) (1) } \\
\text { - Inadequate consultations/intolerance of patients (1) }\end{array}$ & - Patient/parents preferences of staff for central venous access (2) \\
\hline Procedure related & Procedure related \\
\hline - Lack of communication of order-set-availability (1) & $\begin{array}{l}\text { - Institution not used to standardized processes (1) } \\
\text { - State regulation (protocol cannot be initiated before an attending } \\
\text { physician assumes care for a patient) (1) } \\
\text { - Already close to target before intervention (1) }\end{array}$ \\
\hline
\end{tabular}

$E D$, emergency department; $F N$, fever and neutropenia 


\begin{tabular}{|c|c|c|c|c|c|c|}
\hline \multirow{2}{*}{$\begin{array}{l}\text { TTA } \\
\text { Author (year) } \\
\text { Adult patients }\end{array}$} & \multicolumn{2}{|c|}{ Before the intervention } & $\begin{array}{l}\text { After the } \\
\text { Patients }\end{array}$ & $\begin{array}{c}\text { intervention } \\
\text { TTA }\end{array}$ & & OR $[95 \% \mathrm{Cl}]$ \\
\hline & $\mathrm{n}$ & minutes (mean) & $\mathbf{n}$ & minutes(mean) & & \\
\hline $\begin{array}{l}\text { Dang, } 2018 \\
\text { Lim C, } 2012 \\
\text { Meisenberg, } 2015 \\
\text { Van Vilet, } 2011\end{array}$ & $\begin{array}{l}19 \\
73 \\
23 \\
31\end{array}$ & $\begin{array}{l}100 \\
294 \\
252 \\
75.1\end{array}$ & $\begin{array}{c}22 \\
128 \\
33 \\
28\end{array}$ & $\begin{array}{c}27 \\
234 \\
117 \\
32\end{array}$ & $\longmapsto \longmapsto$ & $\begin{array}{l}0.28[0.14,0.55] \\
0.63[0.47,0.84] \\
0.23[0.13,0.42] \\
0.30[0.17,0.53]\end{array}$ \\
\hline \multicolumn{7}{|l|}{ Paediatric patients } \\
\hline $\begin{array}{l}\text { Amado, } 2011 \\
\text { Benne, } 2016 \\
\text { Cash, 2014 } \\
\text { Cohen, 2016 } \\
\text { Lamble, 2015 } \\
\text { Lukes, 2019 } \\
\text { Salstrom, 2015 } \\
\text { Spencer, 2015; ED1 } \\
\text { Spencer, 2015; ED2 } \\
\text { Spencer, 2015; ED3 } \\
\text { Vanderway, 2017 } \\
\text { Vedi, 2015; ED1 } \\
\text { Vedi, 2015; ED2 }\end{array}$ & $\begin{array}{c}24 \\
106 \\
100 \\
100 \\
121 \\
39 \\
53 \\
71 \\
83 \\
211 \\
16 \\
17 \\
10\end{array}$ & $\begin{array}{c}164 \\
207 \\
154 \\
96.9 \\
115 \\
128 \\
164 \\
118.5 \\
163 \\
188 \\
79.6 \\
148 \\
221\end{array}$ & $\begin{array}{c}21 \\
62 \\
30 \\
153 \\
158 \\
12 \\
39 \\
154 \\
365 \\
148 \\
9 \\
20 \\
7\end{array}$ & $\begin{array}{c}55 \\
88.5 \\
95 \\
69.5 \\
60 \\
53 \\
45.2 \\
57 \\
97.5 \\
111.5 \\
41.2 \\
76 \\
65\end{array}$ & (1) & $\begin{array}{l}0.38[0.20,0.70] \\
0.17[0.12,0.25] \\
0.49[0.32,0.74] \\
0.55[0.42,0.71] \\
0.28[0.21,0.36] \\
0.23[0.11,0.46] \\
0.28[0.18,0.43] \\
0.18[0.13,0.25] \\
0.20[0.16,0.27] \\
0.32[0.26,0.40] \\
0.35[0.15,0.84] \\
0.51[0.26,0.99] \\
0.33[0.12,0.94]\end{array}$ \\
\hline & & & & $\Gamma$ & \begin{tabular}{ll|l|l|l|l}
1 & 1 & 1 & 1
\end{tabular} & \\
\hline & & & & 0.08 & $0.22 \quad 0.61$ & \\
\hline
\end{tabular}

Fig. 2 Relative reduction in TTA of studies reporting mean and standard deviation or when those parameters could be estimated

studies that analyzed these $[16,24,27,39,42]$. Likewise none of three studies with data about duration of fever found a significant difference within the groups [16, 25, 32].

For length of hospital stay (LOS), five studies [24, 25, 27 , $29,33]$ did not find a significant difference before and after the intervention. In one of those studies [24], LOS was reduced after an intervention when compared with a historical cohort in a multivariable analysis that adjusted for age, disease type, MASCC risk index, prophylactic antibiotics, central line, and ANC, but not in univariate analysis. Only the pediatric study of Pakakasama et al. [42], who described improved safety, showed that LOS decreased significantly after the intervention. Median LOS was 5 days (range, $1-30$ days) in the 170 episodes of the intervention group, whereas it was 7 days (range, 1-170 days) in the 138 episodes of the control group $(p=0.001)$. In one study [21], LOS was shorter before (mean 11.33 days; $n=30$ ) than after the intervention (mean 17.43 days; $n=23$ ). The authors explain this finding by low number of patients and outliers due to unequal groups. Modification of antibiotics and new infections were not reported by any study.

\section{Subgroup analyses}

Only the planned subgroup analyses between pediatric and adult patients were possible to be undertaken. The main finding was different sources of delays in these two groups (Table 3). Regardless of these different barriers, the durations and reductions were broadly similar: TTA before an intervention varied between an average (median or mean) of 70 $300 \mathrm{~min}$ in adult studies and $79.6-221 \mathrm{~min}$ in pediatric studies. After an intervention, adult studies showed TTAs between 27 and $234 \mathrm{~min}$ and pediatric studies between 41.2$111.5 \mathrm{~min}$. Reduction of the average TTA was between 17.8 $253 \mathrm{~min}$ (or 9-84\%) in adult and $18-156 \mathrm{~min}$ (or $22-73 \%$ ) in pediatric studies.

\section{Discussion}

TTA can be effectively reduced by very different interventions in a wide range of practice settings in both pediatric and adult patients with fever and neutropenia during chemotherapy for cancer. Most of the identified interventions were aimed at modifying the behavior of professionals and implemented at EDs; implementation of guidelines or a checklist were the most often used strategies. Although it is reasonable to assume that publication bias strongly influences this result if only effective interventions are reported, this systematic review helps to identify possible sources of delays and summarizes different strategies to address them.

Guidelines or checklists are useful to address patient-, procedure-, and staff-related factors at once and they were used by $77 \%$ of the included studies. Whereas patient- and procedure-related factors may be more difficult to address otherwise, staff-related factors can be resolved by regular education and training. Unsurprisingly, staff-related factors were also a common reason for delays of TTA and professional interventions were very often used. A systematic review evaluating effective knowledge translation strategies in cancer [48] found that the most promising interventions were professional ones, like educational outreach, audits, and feedbacks. 
In line with these results, our systematic review supports the fact that education and training remain core elements for a successful reduction in TTA. One study showed a reduction in median TTA about $1 \mathrm{~h}$, only by informing staff about already existing guidelines [26]. Unfortunately staff-related issues were also the most often identified barriers to change (Table 4).

Published interventions without professional approaches were all organizational: standing orders allowing nurses to administer antibiotics before calling a physician [29, 30], making antibiotics rapidly available [32], and implementation of a treatment protocol without emphasizing staff education [25]. Among them was the study with the largest TTA reduction [25], with a reduction of mean TTA by $253 \mathrm{~min}$, keeping in mind that this study also reports the longest TTA before the organizational change (mean $300 \mathrm{~min}$ ).

Presentation at the ED has been identified as a reason for longer TTA [15, 49] and more frequent adverse events [14]. This matches our finding that $26(87 \%)$ of the identified studies were undertaken in EDs. High workload due to high patient volumes and lack of training in care of oncology patients may explain this. Three included studies $[26,34,47]$ mentioned ED overcrowding and lack of staff as a barrier to changes; these are factors difficult to address by physicians but should be acknowledged by institutions, where identified.

A study from Canada [50] identified age $>60$ years and lack of caregiver as a risk factor for delayed TTA. In our review, only three studies identified patient-related factors as barriers to change; this may reflect the largely positive input of patients or lack of specific research into these issues.

There were several challenges to summarizing the primary data sources. Through differences in the definitions of key study variables, it was not possible to identify specific interventions that are more likely to be effective than others. The studies were undertaken in different countries and their results must be interpreted in the context of different healthcare provisions. Additionally, the interventions were uneven with respect to type of intervention, number and duration of interventions, what person delivered the intervention, target of behavior, and format used. Because often a number of changes were instituted simultaneously, it is not possible to determine the impact of any single change.

Almost all studies were before and after studies. The identified Hawthorne effect (knowledge of staff about an ongoing study) may have an important influence and therefore followup assessments after the intervention should be undertaken to see whether the improvements are sustainable. Outcomes, such as TTA, may change over time for reasons unrelated to the implemented strategy. If repeated observations before and after an intervention are available, the more robust interrupted time series analysis should be conducted [51]. Assessment of clinical outcomes was limited due to low numbers. Additionally, inclusion of patients at different risk for medical complications creates a triage bias, i.e., faster treatment of patients with worse clinical condition [11] and may therefore mask an effect of shorter TTA in the included studies.

The key strength of this manuscript lies in its thorough application of systematic review methodology. It thus provides the most complete summary of interventions aiming to reduce TTA in patients with FN during chemotherapy for cancer. Additionally, it provides a clearly arranged list of sources of delays and barriers to change TTA, and the undertaken risk of bias assessment helps to judge the validity of the results in TTA reduction.

\section{Conclusion}

TTA can be effectively reduced by very different interventions; however, the direct impact of a shorter TTA on clinical outcomes could not be determined. Education and training were identified as core elements to successfully reduce TTA and remain essential to improve quality of care. Some centers already defined TTA $\leq 60 \mathrm{~min}$ as a valid measure of quality of care $[9,24]$, and although the clinical implication of a shorter TTA is not yet clear [11], our results support the assertion that TTA can be considered a measure of quality of care. This systematic review can be used by care teams as a checklist to identify sources of delays and to evaluate what may be the most important and effective intervention to implement in their specific center to reduce TTA.

Funding information RAA was funded by Krebsliga Schweiz (KFS3645-02-2015). JM was funded during this research by an NIHR Clinical Lecturer Award and BP by an NIHR Post-Doctoral Fellowship.

\section{Compliance with ethical standards}

Conflict of interest The authors declare that they have no conflict of interest.

Open Access This article is distributed under the terms of the Creative Commons Attribution 4.0 International License (http:// creativecommons.org/licenses/by/4.0/), which permits unrestricted use, distribution, and reproduction in any medium, provided you give appropriate credit to the original author(s) and the source, provide a link to the Creative Commons license, and indicate if changes were made.

\section{References}

1. Bodey GP, Buckley M, Sathe YS, Freireich EJ (1966) Quantitative relationships between circulating leukocytes and infection in patients with acute leukemia. Ann Intern Med 64(2):328-340. https://doi.org/10.7326/0003-4819-64-2-328

2. Pizzo PA (1981) Infectious complications in the child with cancer. I Pathophysiology of the compromised host and the initial evaluation and management of the febrile cancer patient. J Pediatr 98(3):341354. https://doi.org/10.1016/S0022-3476(81)80694-4 
3. Hann I, Viscoli C, Paesmans M, Gaya H, Glauser M (1997) A comparison of outcome from febrile neutropenic episodes in children compared with adults: results from four EORTC studies. International Antimicrobial Therapy Cooperative Group (IATCG) of the European Organization for Research and Treatment of Cancer (EORTC). Br J Haematol 99(3):580-588. https://doi.org/ 10.1046/j.1365-2141.1997.4453255.x

4. Luthi F, Leibundgut K, Niggli FK, Nadal D, Aebi C, Bodmer N, Ammann RA (2012) Serious medical complications in children with cancer and fever in chemotherapy-induced neutropenia: results of the prospective multicenter SPOG $2003 \mathrm{FN}$ study. Pediatr Blood Cancer 59(1):90-95. https://doi.org/10.1002/pbc.23277

5. Kuderer NM, Dale DC, Crawford J, Cosler LE, Lyman GH (2006) Mortality, morbidity, and cost associated with febrile neutropenia in adult cancer patients. Cancer 106(10):2258-2266. https://doi.org/ $10.1002 /$ cncr.21847

6. Klastersky J, de Naurois J, Rolston K, Rapoport B, Maschmeyer G, Aapro M, Herrstedt J, Committee EG (2016) Management of febrile neutropaenia: ESMO Clinical Practice Guidelines. Ann Oncol 27(suppl 5):v111-v118. https://doi.org/10.1093/annonc/mdw325

7. Deutsche Gesellschaft für Pädiatrische Infektologie (DGPI) und Gesellschaft Pädiatrische Onkologie und Hämatologie (GPOH) (2016) AWMF S2K Leitlinie: Diagnostik und Therapie bei Kindern mit onkologischer Grunderkrankung, Fieber und Granulozytopenie (mit febriler Neutropenie) außerhalb der allogenen Stammzelltransplantation. AWMF-Registernummer 048/14, finale Version 23.01.2016. https://www.awmf.org/ uploads/tx_szleitlinien/048-0141_S2k_onkologische Grunderkrankung_Fieber_Granulozytopenie_201604 verlaengert. pdf. Accessed 18.04.2018

8. Taplitz RA, Kennedy EB, Bow EJ, Crews J, Gleason C, Hawley DK, Langston AA, Nastoupil LJ, Rajotte M, Rolston K, Strasfeld L, Flowers CR (2018) Outpatient management of fever and neutropenia in adults treated for malignancy: American Society of Clinical Oncology and Infectious Diseases Society of America clinical practice guideline update. J Clin Oncol 36:1443-1453. https://doi.org/ 10.1200/JCO.2017.77.6211

9. McCavit TL, Winick N (2012) Time-to-antibiotic administration as a quality of care measure in children with febrile neutropenia: a survey of pediatric oncology centers. Pediatr Blood Cancer 58(2): 303-305. https://doi.org/10.1002/pbc.23148

10. Koenig C, Morgan J, Ammann RA, Sung L, Phillips B (2019) Protocol for a systematic review of time to antibiotics (TTA) in patients with fever and neutropenia during chemotherapy for cancer (FN) and interventions aiming to reduce TTA. Syst Rev 8(1):82. https://doi.org/10.1186/s13643-019-1006-8

11. Koenig C, Schneider C, Morgan JE, Ammann RA, Sung L, Phillips B (2019) Association of time to antibiotics and clinical outcomes in patients with fever and neutropenia during chemotherapy for cancer: a systematic review. Support Care Cancer. https://doi.org/10. 1007/s00520-019-04961-4

12. Kapil P, MacMillan M, Carvalho M, Lymburner P, Fung R, Almeida B, Van Dorn L, Enright K (2016) Assessment of fever advisory cards (FACs) as an initiative to improve febrile neutropenia management in a regional cancer center emergency department. J Oncol Pract 12(9):e858-e863. https://doi.org/10.1200/JOP.2015. 009183

13. Rosa RG, Goldani LZ (2014) Cohort study of the impact of time to antibiotic administration on mortality in patients with febrile neutropenia. Antimicrob Agents Chemother 58(7):3799-3803. https:// doi.org/10.1128/AAC.02561-14

14. Fletcher M, Hodgkiss H, Zhang S, Browning R, Hadden C, Hoffman T, Winick N, McCavit TL (2013) Prompt administration of antibiotics is associated with improved outcomes in febrile neutropenia in children with cancer. Pediatr Blood Cancer 60(8):12991306. https://doi.org/10.1002/pbc. 24485
15. De La Maza V, Simian D, Castro M, Torres JP, Lucero Y, Sepulveda F, Mazquiaran S, Salazar C, Segovia L, Santolaya ME (2015) Administration time for the first dose of antimicrobials in episodes of fever and neutropenia in children with cancer. Pediatr Infect Dis 34(10):1069-1073. https://doi.org/10.1097/INF.0000000000000820

16. Salstrom JL, Coughlin RL, Pool K, Bojan M, Mediavilla C, Schwent W, Rannie M, Law D, Finnerty M, Hilden J (2015) Pediatric patients who receive antibiotics for fever and neutropenia in less than $60 \mathrm{~min}$ have decreased intensive care needs. Pediatr Blood Cancer 62(5):807-815. https://doi.org/10.1002/pbc.25435

17. Cochrane Effective Practice and Organisation of Care (EPOC) (2018) Data collection checklist https://epoc.cochrane.org/sites/ epoc.cochrane.org/files/public/uploads/datacollectionchecklist.pdf. Accessed 14 May 2018

18. Sterne JA, Hernan MA, Reeves BC, Savovic J, Berkman ND, Viswanathan M, Henry D, Altman DG, Ansari MT, Boutron I, Carpenter JR, Chan AW, Churchill R, Deeks JJ, Hrobjartsson A, Kirkham J, Juni P, Loke YK, Pigott TD, Ramsay CR, Regidor D, Rothstein HR, Sandhu L, Santaguida PL, Schunemann HJ, Shea B, Shrier I, Tugwell P, Turner L, Valentine JC, Waddington H, Waters E, Wells GA, Whiting PF, Higgins JP (2016) ROBINS-I: a tool for assessing risk of bias in non-randomised studies of interventions. BMJ 355:i4919. https://doi.org/10.1136/bmj.i4919

19. Higgins JPT, Green S (2011) Cochrane Handbook for Systematic Reviews of Interventions Version 5.1.0 [updated March 2011]. The Cochrane Collaboration. Available from http://www.handbook. cochrane.org. Accessed 10 Jan 2019

20. Baltic T, Schlosser E, Bedell MK (2002) Neutropenic fever: one institution's quality improvement project to decrease time from patient arrival to initiation of antibiotic therapy. Clin J Oncol Nurs 6(6):337-340. https://doi.org/10.1188/02.CJON.337-340

21. Best JT, Frith K, Anderson F, Rapp CG, Rioux L, Ciccarello C (2011) Implementation of an evidence-based order set to impact initial antibiotic time intervals in adult febrile neutropenia. Oncol Nurs Forum 38(6):661-668. https://doi.org/10. 1188/11.ONF.661-668

22. Dang A, Lauren NG, Whitman M, Fernandez G (2018) Using process improvement tools to improve the care of patients with neutropenic fever in the emergency room. J Oncol Pract 14(1):e73-e81. https://doi.org/10.1200/JOP.2017.026054

23. Hawley EL, Loney M, Wiece M (2011) Development of tools and processes to improve treatment times in patients with febrile neutropenia. Clin J Oncol Nurs 15(5):E53-E57. https://doi.org/10. 1188/11.CJON.E53-E57

24. Keng M, Thallner E, Elson P, Ajon C, Sekeres J, Wenzell C, Seastone D, Gallagher E, Weber C, Earl M, Mukherjee S, Pohlman B, Cober E, Foster V, Yuhas J, Kalaycio M, Bolwell B, Sekeres M (2015) Reducing time to antibiotic administration for febrile neutropenia in the emergency department. J Oncol Pract 11(6):450-455. https://doi.org/10.1200/JOP.2014.002733

25. Ko HF, Tsui SS, Tse JWK, Kwong WY, Chan OY, Wong GCK (2015) Improving the emergency department management of post-chemotherapy sepsis in haematological malignancy patients. Hong Kong Med J 21(1):10-15. https://doi.org/10.12809/ hkmj144280

26. Lim C, Bawden J, Wing A, Villa-Roel C, Meurer DP, Bullard MJ, Rowe BH (2012) Febrile neutropenia in EDs: the role of an electronic clinical practice guideline. Am J Emerg Med 30(1):5-11.e15. https://doi.org/10.1016/j.ajem.2010.08.011

27. Lim FMY, Tong M, Yau CC, Lit ACH, Lo JCK, Lam N, Wong WH, Cheng ACK (2013) Improving service provision to manage chemotherapy-induced neutropenic fever in an oncology unit. Hong Kong J Radiol 16(2):123-130. https://doi.org/10.12809/ hkjr1312157

28. Meisenberg B, Clemons J, Ness J, Faust N, Clance M (2015) Improving hospital performance in the treatment of febrile 
neutropenia. Support Care Cancer 23(2):371-375. https://doi.org/ 10.1007/s00520-014-2377-y

29. Salter C (2005) Clinical pathways in the emergency department: successful implementation of 'adult patients who are febrile following chemotherapy' pathway. Australas Emerg Nurs J 8(1/2):27-34. https://doi.org/10.1016/j.aenj.2005.04.005

30. Van Vliet M, Potting CMJ, Sturm PDJ, Donnelly JP, Blijlevens NMA (2011) How prompt is prompt in daily practice? Earlier initiation of empirical antibacterial therapy for the febrile neutropenic patient. Eur J Cancer Care 20(5):679-685. https://doi.org/10.1111/j. 1365-2354.2011.01264

31. Wells T, Thomas C, Watt D, Fountain V, Tomlinson M, Hilman S (2015) Improvements in the management of neutropenic sepsis: lessons learned from a district general hospital. Clin Med 15(6): 526-530. https://doi.org/10.7861/clinmedicine.15-6-526

32. Amado VM, Vilela GP, Queiroz A Jr, Amaral AC (2011) Effect of a quality improvement intervention to decrease delays in antibiotic delivery in pediatric febrile neutropenia: a pilot study. J Crit Care 26(1):103.e109-103.e112. https://doi. org/10.1016/j.jcrc.2010.05.034

33. Benner CA, Mora E, Mueller E, Seagull FJ, Walkovich K, Johnson K, Halverson S, Rothman E, Hucks G, Younger JG, Nypaver MM (2016) Making improvements in the ED: does ED busyness affect time to antibiotics in febrile pediatric oncology patients presenting to the emergency department? Pediatr Emerg Care 34(5):310-316. https://doi.org/10.1097/PEC.0000000000000882

34. Cash T, Deloach T, Graham J, Shirm S, Mian A (2014) Standardized process used in the emergency department for pediatric oncology patients with fever and neutropenia improves time to the first dose of antibiotics. Pediatr Emerg Care 30(2):91-93. https://doi.org/10.1097/PEC.0000000000000077

35. Cohen C, King A, Lin CP, Friedman GK, Monroe K, Kutny M (2016) Protocol for reducing time to antibiotics in pediatric patients presenting to an emergency department with fever and neutropenia: efficacy and barriers. Pediatr Emerg Care 32(11):739-745. https:// doi.org/10.1097/PEC.0000000000000362

36. Corey AL, Snyder S (2008) Antibiotics in 30 minutes or less for febrile neutropenic patients: a quality control measure in a new hospital. J Pediatr Oncol Nurs 25(4):208-212. https://doi.org/10. 1177/1043454208319971

37. Dobrasz G, Hatfield M, Jones LM, Berdis JJ, Miller EE, Entrekin MS (2013) Nurse-driven protocols for febrile pediatric oncology patients. J Emerg Nurs 39(3):289-295. https://doi.org/10.1016/j. jen.2013.01.014

38. Emerson BL, Prozora S, Jacob A, Clark K, Kotrady D, Edwards L, Ciaburri R, Riera A (2018) An initiative to decrease time to antibiotics for patients with fever and neutropenia. Am J Med Qual 34(2): 158-164. https://doi.org/10.1177/1062860618792305

39. Lamble A, Nguyen T, Lindemulder S, Spiro DMS, Nolt D, Stork L (2015) A clinical pathway to reduce time to antibiotic administration in pediatric cancer patients with fever and potential neutropenia. J Clin Pathways 1(2):33-42

40. Lukes T, Schjodt K, Struwe L (2019) Implementation of a nursing based order set: improved antibiotic administration times for pediatric ED patients with therapy-induced neutropenia and fever. J Pediatr Nurs 46:78-82. https://doi.org/10.1016/j.pedn.2019.02.028
41. Monroe K, Cohen CT, Whelan K, King A, Maloney L, Deason J, Nichols JC, Friedman GK, Kutny M, Hayes L (2018) Quality initiative to improve time to antibiotics for febrile pediatric patients with potential neutropenia. Pediatr Qual Saf 3(4):e095. https://doi. org/10.1097/pq9.0000000000000095

42. Pakakasama S, Surayuthpreecha K, Pandee U, Anurathapan U, Maleewan V, Udomsubpayakul U, Butthep P, Santanirand P, Sirachainan N, Hongeng S (2011) Clinical practice guidelines for children with cancer presenting with fever to the emergency room. Pediatr Int 53(6):902-905. https://doi.org/10.1111/j.1442-200X. 2011.03363.x

43. Spencer S, Nypaver M, Hebert K, Benner C, Stanley R, Cohen D, Rogers A, Goldstick J, Mahajan P (2017) Successful emergency department interventions that reduce time to antibiotics in febrile pediatric cancer patients. BMJ Qal Improv Rep 6(1). https://doi.org/ 10.1136/bmjquality.u212406.w4933

44. Vanderway J, Vincent C, Walsh SM, Obrecht J (2017) Implementation of a pathway for the treatment of fever and neutropenia in pediatric patients with cancer. J Pediatr Oncol Nurs 34(5):315-321. https://doi.org/10.1177/1043454217691231

45. Vedi A, Pennington V, O'Meara M, Stark K, Senner A, Hunstead P, Adnum K, Londall W, Maurice L, Wakefield C, Cohn RJ (2015) Management of fever and neutropenia in children with cancer. Support Care Cancer 23(7):2079-2087. https://doi.org/10.1007/ s00520-014-2572-x

46. Volpe D, Harrison S, Damian F, Rachh P, Kahlon PS, Morrissey L (2012) Improving timeliness of antibiotic delivery for patients with fever and suspected neutropenia in a pediatric emergency department. Pediatrics 130:e201-e210. https://doi.org/10.1542/peds. 2012-0153

47. Yoshida H, Leger KJ, Xu M, Migita RT, Rutledge JC, Pollard JA, Kroon L, Mazor SS, Moon A, Rutman LE (2018) Improving time to antibiotics for pediatric oncology patients with suspected infections: an emergency department-based quality improvement intervention. Pediatr Emerg Care 34(1):47-52. https://doi.org/10.1097/ PEC.0000000000001367

48. Brouwers MC, Garcia K, Makarski J, Daraz L, Evidence Expert Panel, KT for Cancer Control in Canada Project Research Team (2011) The landscape of knowledge translation interventions in cancer control: what do we know and where to next? A review of systematic reviews. Implement Sci 6:130. https://doi.org/10.1186/ 1748-5908-6-130

49. Sammut SJ, Mazhar D (2012) Management of febrile neutropenia in an acute oncology service. QJM 105(4):327-336. https://doi.org/ 10.1093/qjmed/hcr217

50. Szwajcer D, Czaykowski P, Turner D (2011) Assessment and management of febrile neutropenia in emergency departments within a regional health authority-a benchmark analysis. Curr Oncol 18(6): 280-284. https://doi.org/10.3747/co.v18i6.841

51. Robinson PD, Dupuis Lee L, Tomlinson G, Phillips B, Greenberg M, Sung L (2016) Strategies facilitating practice change in pediatric cancer: a systematic review. Int J Qual Health Care 28(4):426-432. https://doi.org/10.1093/intqhe/mzw052

Publisher's note Springer Nature remains neutral with regard to jurisdictional claims in published maps and institutional affiliations. 